\title{
SWIMMING EXPERIENCES AND ABILITIES OF NINE YEAR OLDS
}

\author{
J. LANGLEY, PhD and P. A. SILVA, PhD ) \\ The Dunedin Multidisciplinary Health \& Development Research Unit, Department of Paediatrics \& Child Health, \\ University of Otago Medical School, P.O. Box 913, Dunedin
}

\section{ABSTRACT}

As part of a longitudinal study of children, 941 mothers were asked to report on their childrens' swimming experiences and abilities. At age nine, twenty-nine per cent of the children could swim only a few strokes or not at all. A disproportionate number of children who could swim more than a few strokes came from high socio-economic backgrounds, from families where one or more of the parents could swim, and which scored higher on an index of active recreational orientation. There were no significant sex differences in swimming ability. There were 97 incidents reported where a child had been in difficulties while in water and had to be rescued. The importance of collecting data on such incidents is discussed.

\section{INTRODUCTION}

Drowning is the second major cause of injury mortality among children in New Zealand (Langley, 1983). In 1979, there were 185 children who died as a result of an injury. Sixty-nine died as a result of motor vehicle traffic related injuries, and forty from drowning. Near drowning incidents receive less prominence since there is often no associated injury, and thus they are not recorded in morbidity statistics. Nevertheless, these incidents are relatively common. For example, Fergusson, Harwood and Shannon (1983) reported 94 domestic swimming pool incidents in the first five years of life in a cohort of 1,123 children. Most of these incidents were considered relatively minor. Six were considered to have been potentially fatal but, nevertheless, required no medical treatment. Typically, these events are described as immersion incidents (Pearn and Nixon, 1977; Walker and Middelkamp, 1981). Data on immersion incidents not resulting in hospitalisation for older New Zealand children are not available.

There are several countermeasures which can be implemented to reduce childhood drownings and near drownings. For the young child, emphasis is placed on modifying the environment (e.g. fencing swimming pools) and parental vigilance. As children get older, greater emphasis is placed on teaching the child to swim. Despite the importance of the latter strategy, little is known of children's swimming ability and its determinants.

This study represents a follow up of an earlier investigation which reported swimming experiences and abilities of seven year olds (Langley, Silva and Williams, 1981). In addition to obtaining more detailed information on swimming ability, the investigation also sought to examine the relationship of parents' swimming ability, the sex of the child, socio-economic status, and the family's active recreational orientation to the child's swimming ability.

\section{METHOD}

The data were collected during the ninth phase of the Dunedin Multidisciplinary Health and Development Study. This is a longitudinal study of the health, development and behaviour of a sample of New Zealand children who were born at Dunedin's only obstetric hospital between 1st April, 1972 and 31st March, 1973. The sample was drawn from all children born at Queen Mary Hospital in that year whose mothers had been resident in the metropolitan area and who still lived in the Dunedin area or the province of Otago when the children were three years of age. Of the 1,139 children who were eligible for inclusion in the sample at age three, 955 were assessed near their ninth birthday. The sample was generally of higher socio-economic groups and under-representative of Maoris and Polynesians compared with New Zealand as a whole. A complete description of the nature of the study and the study sample is provided by McGee and Silva (1982).
At the nine year assessment, mothers were asked; whether they could swim, to provide details of their child's swimming experiences and abilities, and whether their child had ever been in difficulties in water and had to be rescued.

The socio-economic status of the child was based on the occupation of the father or breadwinner and coded according to the Elley and Irving (1976) socio-economic index. The Elley and Irving Scale groups the occupations listed in the New Zealand census into six ordered levels, ranging from group 1 (high) to group 6 (low).

The extent to which the family participated actively in various recreational and sporting activities was assessed by the Active Recreational Orientation subscale of the Family Environment Scale (Moos and Moos, 1981).

Results were analysed using chi-squared tests and a student's t-test. The Bonferroni inequality was used to control for possible inflation of the Type 1 error rate (Grove and Andreasen, 1982). Thus, the four independent variables were tested at $p<0.01$ ( 0.05 divided by 4$)$ to maintain the overall Type 1 error rate at 0.05 .

\section{RESULTS}

Eight hundred and twenty-two (87\%) of the 941 mothers who completed the questionnaire reported that they could swim. Slightly more $(88 \%)$ of the mothers reported that their husbands could swim. Twenty per cent of the children were members of a swimming club. The majority of mothers $(95 \%)$ confirmed that their child could immerse himself or herself completely in water with confidence (i.e. open eyes, exhale, relax). Ninety-seven $(10 \%)$ children were considered to have been in difficulties in water and had to be rescued. There were no injuries associated with these events, nor were there any significant sex differences $\left(X^{2}=\right.$ $0.01 \mathrm{df} p>0.05)$.

Table I sets out the distance the child was considered to be able to swim. In those cases where it was indicated that the child could swim ( $N=823$ ), the mother was asked who had been the child's principal swimming instructor while learning. In 49 per cent of the cases, this was a swimming instructor. In 32 per cent of the cases the instructor was a school teacher, and in 11 per cent of the cases a parent. The remaining 8 per cent of the children were taught by other persons.

For subsequent analyses, those children who were not able to swim or could only swim a few strokes were categorised as "non-swimmers" and the remainder, those who could swim 10 metres or more, were categorised as "swimmers". Table II sets out the results for sex, socio-economic status, parents' swimming ability and the families' active recreational orientation. There was no significant sex differences 
between non-swimmers and swimmers. Those who were swimmers were more often from high socio-economic backgrounds, more often had parents who could swim and came from families which had significantly higher mean scores on a measure of active recreational orientation. Since there was no socio-economic status index for children without a father figure, a separate analysis was undertaken which examined the relationship between parent status (solo versus non-solo) and swimming ability. This analysis showed that there was no significant relationship between the two variables.

TABLE I

Children's reported swimming ability

\begin{tabular}{lcc}
\hline & N & $\%$ \\
Not able to swim & 118 & 13 \\
Only a few strokes & 150 & 16 \\
10 metres & 239 & 25 \\
25 metres & 259 & 28 \\
50 metres & 90 & 10 \\
$50+$ metres & 85 & 9 \\
TOTAL & 941 & 101 \\
\hline
\end{tabular}

TABLE II

Sex, social factors and swimming ability $(N=941)$

\begin{tabular}{|c|c|c|c|c|}
\hline \multirow[b]{3}{*}{ Sex } & \multicolumn{4}{|c|}{ Children } \\
\hline & \multicolumn{2}{|c|}{ Non-swimmers } & \multicolumn{2}{|c|}{ Swimmers } \\
\hline & $\mathbf{N}$ & $\%$ & $\mathbf{N}$ & $\%$ \\
\hline Male & 132 & (49) & 323 & (48) \\
\hline Female & 136 & (51) & 350 & (52) \\
\hline \multirow[t]{2}{*}{ TOTAL } & 268 & $(100)$ & 673 & (100) \\
\hline & \multicolumn{2}{|c|}{$x^{2}=0.07$} & \multicolumn{2}{|c|}{ Idf $p>0.05$} \\
\hline Socio-economic Status & $\mathbf{N}$ & $\%$ & $\mathbf{N}$ & $\%$ \\
\hline 1 & 16 & (7) & 87 & (15) \\
\hline 2 & 31 & (13) & 83 & (14) \\
\hline 3 & 60 & (25) & 167 & (29) \\
\hline 4 & 78 & (33) & 170 & (29) \\
\hline 5 & 27 & (11) & 49 & (8) \\
\hline 6 & 24 & (10) & 23 & (4) \\
\hline TOTAL & 236 & (99) & 579 & (99) \\
\hline$x^{2}=23.4$ & \multicolumn{2}{|r|}{$p<0.001$} & \multicolumn{2}{|c|}{ eta $^{2}=0.02$} \\
\hline (Missing Cases $=41$ ) & \multicolumn{4}{|c|}{ (No father figure $=85$ ) } \\
\hline Parents' Swimming Ability & $\mathbf{N}$ & $\%$ & $\mathbf{N}$ & $\%$ \\
\hline Neither parent can swim & 20 & (7) & 6 & (1) \\
\hline Only one parent can swim & 82 & (31) & 140 & (21) \\
\hline Both parents can swim & 166 & (62) & 527 & (78) \\
\hline TOTAL & 268 & $(100)$ & 673 & $(100)$ \\
\hline$x^{2}=44.7$ & $2 \mathrm{df}$ & $p<0.001$ & \multicolumn{2}{|c|}{ eta ${ }^{2}=0.04$} \\
\hline \multicolumn{5}{|l|}{$\begin{array}{l}\text { Parents' Active Recreational } \\
\text { Orientation }\end{array}$} \\
\hline Mean Scores (SD) & \multicolumn{2}{|c|}{$5.4( \pm 2.3)$} & \multicolumn{2}{|c|}{$6.5( \pm 1.8)$} \\
\hline$t=7.56$ & $882 \mathrm{df}$ & $p<0.001$ & eta ${ }^{2}$ & 0.06 \\
\hline \multicolumn{5}{|l|}{ (Missing Cases $=57$ ) } \\
\hline
\end{tabular}

\section{DISCUSSION}

The finding that 87 per cent of the mothers could swim is similar to that reported by Buttle and Rhind (1978a) in a telephone survey of 100 households, where in 92 cases the respondent was a mother. In that survey, 81 per cent of the respondents reported that they were able to swim.

At age seven, 53 per cent of the children were reported as being able to swim at least "a few strokes" (Langley et al 1981). The results presented here show that 87 per cent of the children were able to achieve this level of performance by their ninth birthday. This improvement probably reflects increased school swimming programmes and private instruction with increasing age. Whilst the ability to swim a few strokes is clearly preferable to not being able to swim at all, there are those who would consider this performance to indicate inability to swim. Using Nixon, Pearn and Dugdale's (1979) swimming ability criteria of 10 metres or more, 29 per cent of the sample were unable to swim. This finding is of concern given that next to preschoolers, the 5-9 age group is at the greatest risk of drowning (Department of Health, 1982). Moreover, the older child is more likely to drown in non-domestic environments (e.g. rivers, sea) which, unlike domestic environments, are from a practical viewpoint impossible to modify to minimise the risk of drowning. Under these situations an ability to swim assumes greater importance.

The finding that 71 per cent of the children were able to swim 10 metres or more by their ninth birthday is less than that reported in the Queensland study where the comparable figure was 84 per cent. The higher percentage for Queensland is probably attributable to a variety of factors, including high temperatures, and a higher rate of private swimming pool ownership (Nixon et al, 1979).

Swimming ability alone should not be seen as the ultimate panacea. The Brisbane Drowning Study showed that approximately one in every five children over the age of five years who drowned could nevertheless swim (Pearn, Nixon and Wilkey, 1976). Clearly, a mix of strategies is required to minimise drownings. In addition to ensuring that children can swim, other strategies include ensuring life jackets are worn and when appropriate, bathing and swimming in sea areas patrolled by surf life savers, developing underwater skills, and ensuring the victim receives rapid and appropriate first aid (Langley, 1983).

Buttle and Rhind (1978b) reported that when asked whose duty it was to teach the children to swim, 49 per cent of the parents saw it as their duty. The results show that the parents relied on swimming instructors and teachers to provide the principal instruction.

The results show that there were no significant differences between boys and girls in swimming ability. Nixon et al (1979) reported the same finding in a Queensland study. These results suggest that the repeatedly demonstrated higher immersion rate among boys cannot be attributable to sex differences in swimming ability. There was a significant relationship between socio-economic status and swimming ability, with swimmers being over-represented in the high socio-economic levels. This finding is similar to that reported by Nixon et al (1979). Children who could swim were more likely to come from families where both parents could swim than from families where only one parent could swim or neither could. The children who could swim were shown to have come from families which placed significantly more emphasis on active recreation than those families where the child could not swim. There are a variety of plausible explanations for these findings. High socioeconomic groups are probably more likely to have their own swimming pools and be in a position to pay for private swimming instruction. Those parents who can swim are probably more likely to expose their children to water environments and to encourage them to participate in swimming and water-related activities. Similarly, parents with active recreational interests are probably more likely to 
be interested in going swimming and participating in water sports, thus encouraging their children to swim. Despite the statistical significance of the associations between socioeconomic status, parents' swimming ability, parents' active recreational orientation, and child's swimming ability, no single association accounted for more than six per cent of the variance in swimming ability. Factors which may be more important in determining swimming ability include whether there is swimming instruction at school, and distances families live from beaches, rivers and swimming pools.

The 97 immersion incidents reported are probably an underestimate given the seven year recall period. Whilst the data is not directly comparable with that produced by Fergusson et al (1983) their findings suggest that the number of incidents reported here should have been higher, particularly when it is considered that this study was not confined to swimming pool incidents. Aside from the differences in recall period, there are several other possible factors which may account for the lower reported rate in Dunedin. The most likely explanation is the difference in climate. Christchurch receives approximately 18 per cent more sunshine hours each year and has a higher mean summer temperature than Dunedin (Department of Statistics, 1982). Thus it seems likely that Christchurch children described by Fergusson et al (1983) would be exposed to water hazards of all types more often.

The absence of a sex difference in the immersion incidents reported here suggests that control should be exercised in extrapolating from immersion incidents resulting in injury, where boys are at greater risk (Department of Health, 1980) to incidents which do not result in any injury.

In 1979 there were 40 children who died as a result of drowning in New Zealand (Department of Health, 1982). Hospital and Selected Morbidity Data (Department of Health, 1980) for the same year shows that 63 children were either discharged, transferred from or died in public or private hospitals as a result of immersion incidents. These statistics, coupled with the data from this study and that of Fergusson et al (1983), demonstrate that the majority of immersion incidents do not result in injury and do not come to the attention of the health services. The relative rarity of mortality and the low morbidity rate necessitates that the circumstances of immersion incidents not resulting in injury be described if countermeasures are to be developed and evaluated more rapidly than at present.

\section{ACKNOWLEDGEMENTS}

The Dunedin Multidisciplinary Health and Development Research Unit is supported by the Medical Research Council of New Zealand, the Departments of Education and Health, and involves several departments of the University of Otago. Much of the data is gathered by volunteer workers from the Dunedin community. The authors are indebted to the many people whose contribution makes this ongoing study possible.

The research was undertaken while the first author was a recipient of a Medical Research Council Training Fellowship in the Dunedin Multidisciplinary Health and Development Research Unit. This paper was written with the aid of a grant from the Accident Compensation Corporation. The ideas and opinions expressed in this paper are not necessarily those of organisations which funded this research.

\section{References}

Buttle, F. and Rhind, R. 1978a "Research into swimming and rescue breathing skills and life jacket use - a telephone survey". Market Research Centre, Massey University, Palmerston North.

Buttle, F and Rhind, R, 1978b "Research into parental control of children with respect to water safety - a personal interview survey". Market Research Centre, Massey University, Palmerston North

Department of Health, 1980. Mortality and Demographic Data, 1979. Department of Health, Wellington.

Department of Health, 1982. Hospital and Selected Morbidity Data, 1979. Department of Health, Wellington.

Department of Statistics, 1982. New Zealand Official Yearbook. Government Printer, Wellington.

Elley, W. B. and Inving, J. C., 1976 "Revised socio-economic index for New Zealand". NZ J.Educational Studies 11: 23-36.

Fergusson, D. M., Harwood, L. J. and Shannon, F. T., 1983 “Domestic swimming pool accidents to pre-school children". NZ Med.J. 96: 724-726.

Grove, W. M. and Andreasen, N. C., 1982 "Simultaneous tests of many hypotheses in exploratory research". J.Nervous and Mental Disease 170: 3-8.

Langley, J. D., Silva, P. A. and Williams, S. M., 1981 "Swimming experiences and abilities of seven year olds". NZ J.Health, Phys. Ed.and Rec. 14: 45-46.

Langley, J. D., 1983 "Fencing of private swimming pools in New Zealand". Community Health Studies 7: 285-289.

McGee, R. and Silva, P. A., 1982 "A thousand New Zealand children: their health and development from birth to seven". Medical Research Council of New Zealand, Special Report Series, Auckland.

Moos, R. and Moos, B., 1981. Family Environment Scale Manual. California Consulting Psychologists Press, Palo Alto.

Nixon, J. W., Pearn, J. H. and Dugdale, A. E., 1979 "Swimming ability of children. A survey of $\mathbf{4 0 0 0}$ Queensland children in a high drowning region". Med.J.Aust. 2: 271-272.

Pearn, J. H. and Nixon, J., 1977 "Swimming pool immersion accidents. An analysis from the Brisbane Drowning Study". Med.J.Aust. 1: 432-437.

Pearn, J., Nixon, J. and Wilkey, I., 1976 "Freshwater drowning and near drowning accidents involving children". Med.J.Aust. 2: 942-946.

Walker, S. and Middelkamp, N. J., 1981 "Pail immersion accidents". Clinical Pediatrics 20: 341-343. 